\title{
Task shifting redefined: removing social and structural barriers to improve delivery of HIV services for people who inject drugs
}

\author{
Lianping $\mathrm{Ti}^{1}$ and Thomas Kerr ${ }^{1,2^{*}}$
}

\begin{abstract}
HIV infection among people who inject drugs (IDU) remains a major global public health challenge. However, among IDU, access to essential HIV-related services remains unacceptably low, especially in settings where stigma, discrimination, and criminalization exist. These ongoing problems account for a significant amount of preventable morbidity and mortality within this population, and indicate the need for novel approaches to HIV program delivery for IDU. Task shifting is a concept that has been applied successfully in African settings as a way to address health worker shortages. However, to date, this concept has not been applied as a means of addressing the social and structural barriers to HIV prevention and treatment experienced by IDU. Given the growing evidence demonstrating the effectiveness of IDU-run programs in increasing access to healthcare, the time has come to extend the notion of task shifting and apply it in settings where stigma, discrimination, and criminalization continue to pose significant barriers to HIV program access for IDU. By involving IDU more directly in the delivery of HIV programs, task shifting may serve to foster a new era in the response to HIV/AIDS among IDU.
\end{abstract}

Keywords: Task shifting, People who inject drugs, Stigma and discrimination, HIV services

The HIV/AIDS epidemic among people who inject drugs (IDU) remains a major public health challenge globally. This epidemic persists despite the fact that a range of effective preventive interventions and treatments exist [1]. A review by the Reference Group to the UN on HIV and Injecting Drug Use concluded that access to HIV prevention, treatment and care among IDU globally was extremely low and that urgent action was needed to rectify this situation [2]. Various factors contributing to low access to HIV prevention and treatment among IDU have been identified, including the unavailability of programs, as well as an overreliance on drug law enforcement, incarceration, and mandatory drug detention programs as primary responses to the harms of injection drug use [3-6].

A growing body of literature highlights a range of downstream social and behavioural impacts of the global emphasis on drug law enforcement. For example, fear of

\footnotetext{
* Correspondence: uhri-tk@cfenet.ubc.ca

'British Columbia Centre for Excellence in HIV/AIDS, St. Paul's Hospital, 608-1081 Burrard Street, Vancouver, BC V6Z 1Y6, Canada

${ }^{2}$ Department of Medicine, St. Paul's Hospital, University of British Columbia, 608-1081 Burrard Street, Vancouver, BC V6Z 1Y6, Canada
}

confrontations with police perpetuates unwillingness among IDU to access essential HIV-related services [7,8]. The emphasis on punishment of IDU for their behaviours also fuels negative public opinion of this population, including among healthcare workers, which makes ensuring access to prevention and treatment of HIV challenging if not impossible [8,9]. For example, throughout the Asia-Pacific region, many IDU encounter delays in the provision of healthcare services, refusal of treatment by healthcare workers, as well as breaches of confidentiality, including sharing of information between healthcare workers and police $[10,11]$. In some settings, individuals are registered as drug users within national or regional databases upon seeking care or treatment [8]. Negative physician attitudes towards HIV-positive IDU have also led to suboptimal ART treatment and care for this subpopulation due to concerns over non-adherence and antiretroviral resistance [11-13]. Pervasive stigma and the associated self-imposed isolation that often results can also render individuals reluctant to access services due to fears that family, community members, and employers may shun them for their drug using behaviours [14-16]. Collectively, these barriers to HIV 
prevention and treatment highlight the urgent need for novel methods of healthcare delivery for this population.

One concept that has been applied to improve the delivery of HIV services in African settings is that of task shifting. Defined as the systematic delegation of tasks from specialized cadres to cadres with less training such as nurses or lay workers, task shifting has been used as an effective strategy to address the current healthcare worker shortage in many African countries [17-20]. A body of literature supports the use of task shifting as a successful approach in delivering healthcare services including HIV testing, counseling, and ART treatment by lay workers [21-24]. In addition to the success of this model among heterosexual populations within resource limited settings, a systematic review has revealed that task shifting can also be applied effectively to more marginalized populations, including men who have sex with men [25]. In addition to the role of task shifting as a means to improve coverage of HIV services, this concept has also been applied to alleviate the economic burden imposed on many developing countries [18]. Due to recent financial cutbacks made by the Global Fund to Fight AIDS, Tuberculosis and Malaria, the organization is now considerably more limited in its ability to respond to the global HIV pandemic [26,27]. In a time when resources are scarce, task shifting may help to relieve this situation and attempt to avert the HIV/AIDS crisis.

In light of the ongoing problems in ensuring access to essential HIV prevention and treatment services for IDU, there may be an opportunity to reconceptualize task shifting as a way of overcoming social and structural barriers to HIV-related services. A large body of evidence indicates that peer-run initiatives can extend the reach and effectiveness of conventional public health programs by reaching high-risk IDU [28-30]. Accordingly, the WHO, UNODC, UNAIDS Technical Guide recommend community-based outreach methods as an essential approach for service delivery [1]. However, the involvement of IDU in providing HIV services need not be limited to those efforts that aim to extend the reach of existing programs and may have value in other areas. Shifting HIV services from professional healthcare workers to peers may also serve to address the existing stigma that IDU experience within healthcare settings, thereby improving access to these services, especially in the Asia-Pacific region where the annual prevalence of HIV testing among IDU is as low as $20 \%$ [31]. By creating peer-involved HIV testing clinics and pairing physicians with peers, IDU may be more likely to use these services without fear of being discriminated by healthcare workers or fear of being registered as drug users within official registries. Indeed, past research has shown that drug-user led interventions are more acceptable to IDU than conventional public health programs, [32-34] and that this is due in part to perceived acceptance of their drug use behaviors by their peers [28,29]. In this sense, there may also be potential for peer-delivered HIV services that do not involve healthcare professionals, as many IDU may prefer to have their peers deliver these services to avoid frequent interactions with healthcare workers.

Additionally, task shifting may avert some problems caused by police in countries with a heavy reliance on law enforcement. By shifting delivery of care from healthcare professionals to peers, or by incorporating peer workers into professionally-led services, a reduction in stigma and discrimination in these settings may be achieved [32]. Likewise, this type of shift in service delivery may address some concerns among IDU about information sharing between public health systems and enforcement officials.

While there is potential for task shifting to reduce stigma and discrimination in these settings and thus provide greater coverage of HIV prevention and treatment services, it is important to recognize the political barriers that may restrict the wide implementation of these programs; particularly, the lack of governmental and public support for harm reduction programs. Therefore, in order for task shifting to be successfully and sustainably implemented within these settings, there is still a need to shift public and policy thinking towards harm reduction practices through the collective involvement of the community, researchers, service providers, advocates, and policy makers.

HIV/AIDS among IDU has taken a massive toll in terms of human suffering and economic impacts in countries throughout the world. High rates of preventable HIV infection, HIV-related morbidity and mortality among IDU, as well as increasing expenditures on HIV-related care and treatment services are major consequences of suboptimal HIV prevention and treatment. There is now an obvious need for innovation in the delivery of programs and services for IDU. Given the evidence indicating positive benefits of peer-led interventions for IDU, as well as the success of task shifting in settings with human health resource shortages, shifting the delivery of conventional HIV/AIDS programs and services to IDU themselves may serve to address the severe stigmatization and discrimination that characterizes the existing healthcare context in many settings hard hit by IDU-driven HIV epidemics. In turn, this novel approach to task shifting may foster a new era in the response to HIV among IDU.

\section{Competing interests}

The authors declare that they have no competing interests.

\section{Authors' contributions}

The specific contributions of each author are as follows: LT prepared the first draft of the manuscript; TK provided critical comments on the first draft of the manuscript; Both authors approved the final version to be submitted.

Received: 23 August 2012 Accepted: 24 September 2013

Published: 4 October 2013 


\section{References}

1. WHO, UNODC, UNAIDS: WHO, UNODC, UNAIDS technical guide for countries to set targets for universal access to HIV prevention, treatment and care for injecting drug users. Geneva: WHO; 2009.

2. Reference Group to the UN on HIV and injecting drug use: Consensus Statement of the Reference Group to the United Nations on HIV and Injecting Drug Use 2010. New South Wales: Reference Group to the UN on HIV and injecting drug use; 2010.

3. Mathers B, Degenhardt L, Ali H, Wiessing L, Hickman M, Mattick R, Myers B, Ambekar A, Strathdee S: HIV prevention, treatment, and care services for people who inject drugs: a systematic review of global, regional, and national coverage. Lancet 2010, 375:1014-1028.

4. Csete J, Kaplan K, Hayashi K, Fairbairn N, Suwannawong P, Zhang R, Wood E, Kerr T: Compulsory drug detention center experiences among a community-based sample of injection drug users in Bangkok, Thailand. BMC Int Health Hum Rights 2011, 11:11.

5. Wolfe D: Paradoxes in antiretroviral treatment for injecting drug users: Access, adherence and structural barriers in Asia and the former Soviet Union. Int J Drug Policy 2007, 18:246-254.

6. Small W, Wood E, Betteridge G, Montaner J, Kerr T: The impact of incarceration upon adherence to HIV treatment among HIV-positive injection drug users: a qualitative study. AIDS Care 2009, 21:708-714.

7. Beyrer C, Malinowska-Sempruch K, Kamarulzaman A, Kazatchkine M, Sidibe M, Strathdee S: Time to act: A call for comprehensive responses to HIV in people who use drugs. Lancet 2010, 376:551-563.

8. Human Rights Watch, Thai AIDS Treatment Action Group: Deadly denial. Thailand: Barriers to HIV/AIDS treatment for people who use drugs in Thailand; 2007.

9. Chan K, Stoove M, Sringernyuang L, Reidpath D: Stigmatization of AIDS patients: Disentangling Thai nursing students' attitudes towards HIV/ AIDS, drug use, and commercial sex. AIDS Behav 2008, 12:146-157.

10. Paxton S, Gonzales G, Uppakaew K, Abraham K, Okta S, Green C, Nair K, Parwati Merati T, Thephthien B, Marin M, Quesada A: AIDS-related discrimination in Asia. AIDS Care 2005, 17:413-424.

11. Ding L, Landon B, Wilson I, Wong M, Shapiro M, Cleary P: Predictors and Consequences of Negative Physician Attitudes Toward HIV-Infected Injection Drug Users. Arch Intern Med 2005, 165:618-623.

12. Escaffre N, Morin M, Bouhnik A, Fuzibet J, Gastaut J, Obadia Y, Moatti J. Injecting drug users' adherence to HIV antiretroviral treatments: Physicians' beliefs. AIDS Care 2000, 12:723-730.

13. Wood E, Kerr T, Tyndall M, Montaner J: A review of barriers and facilitators of HIV treatment among injection drug users. AIDS 2008, 22:1247-1256.

14. Ford K, Wirawan D, Sumantera G, Sawitri A, Stahre M: Voluntary HIV testing, disclosure, and stigma among injection drug users in Bali, Indonesia. AIDS Educ Prev 2004, 16:487-498.

15. Rudolph A, Davis W, Quan V, Ha T, Minh N, Gregowski A, Salter M, Celentano D, Go V: Perceptions of community- and family-level injection drug user (IDU)- and HIV-related stigma, disclosure decisions and experiences with layered stigma among HIV-positive IDUs in Vietnam. AIDS Care 2012, 24:239-244.

16. Johnson M, Chesney M, Neilands T, Dilworth S, Remien R, Weinhardt L, Wong L, Morin S, NIMH Health Living Project Team: Disparities in Reported Reasons for Not Initiating or Stopping Antiretroviral Treatment Among a Diverse Sample of Persons Living with HIV. J Gen Int Med 2008, 24:247-251

17. Callaghan M, Ford N, Schneider H: A systematic review of task-shifting for HIV treatment and care in Africa. Hum Resour Health 2010, 8

18. Brugha R, Kadzandira J, Simbaya J, Dicker P, Mwapasa V, Walsh A: Health workforce responses to global health initiatives funding: a comparison of Malawi and Zambia. Hum Resour Health 2010, 8.

19. Curran K, Njeuhmeli E, Mirelman A, Dickson K, Adamu T, Cherutich P, Mahler H, Fimbo B, Mavuso T, Albertini J, Fitzgerald L, Bock N, Reed J, Castor D, Stanton D: Voluntary Medical Male Circumcision: Strategies for Meeting the Human Resource Needs of Scale-Up in Southern and Eastern Africa. PLoS Med 2011, 8:e1001129.

20. Shumbusho F, Van Griensven J, Lowrance D, Turate I, Weaver M, Price J, Binagwaho A: Task Shifting for Scale-up of HIV Care: Evaluation of NurseCentered Antiretroviral Treatment at Rural Health Centers in Rwanda. PLoS Med 2009, 6:e1000163.

21. Jaffar S, Amuron B, Foster S, Birungi J, Levin J, Namara G, Nabiryo C, Ndembi N, Kyomuhangi R, Opio A, Bunnell R, Tappero J, Mermin J, Coutinho A,
Grosskurth H, Jinja Trial Team: Rates of virological failure in patients treated in a home-based versus a facility-based HIV-care model in Jinja, southeast Uganda: A cluster-randomised equivalence trial. Lancet 2009, 374:2080-2089

22. Sanjana P, Torpey K, Schwarzwalder A, Simumba C, Kasonde P, Nyirenda L, Kapanda R, Kakungu-Simpungwe M, Kabaso M, Thompson C: Task-shifting HIV counselling and testing services in Zambia: The role of lay counsellors. Hum Resour Health 2009, 7.

23. Bemelmans M, Van Den Akker T, Ford N, Philips M, Zachariah R, Harries A, Schouten E, Hermann K, Mwagomba B, Massaguoi M: Providing universal access to antiretroviral therapy in Thyolo, Malawi through task shifting and decentralization of HIV/AIDS care. Trop Med Int Health 2010, $15: 1413-1420$

24. Selke H, Kimaiyo S, Sidle J, Vedanthan R, Tierney W, Shen C, Denski C, Katschke A, Wools-Kaloustian K: Task-shifting of antiretroviral delivery from health care workers to persons living with HIV/AIDS: clinical outcomes of a community-based program in Kenya. J Acquir Immune Defic Syndr 2010, 55:483-490.

25. Pedrana A, Guy R, Bowring A, Hellard M, Stoove M: Community models of HIV testing for men who have sex with men (MSM): Systematic Review 2011. Burnet Institute: Melbourne; 2011.

26. Boseley S: Crisis looms as Global Fund forced to cut back on Aids, malaria and TB grants. The Guardian 2011

27. York G: Economic crisis hits health aid that has helped millions as donors cut back. The Globe and Mail 2011.

28. Kerr T, Hayashi K, Fairbairn N, Kaplan K, Suwannawong P, Zhang R, Wood E: Expanding the reach of harm reduction in Thailand: Experiences with a drug user-run drop-in centre. Int J Drug Policy 2010, 21:255-258.

29. Hayashi K, Wood E, Wiebe L, Qi J, Kerr T: An external evaluation of a peer-run outreach-based syringe exchange in Vancouver, Canada. Int J Drug Policy 2010, 21:418-421.

30. Smyrnov P, Broadhead R, Datsenko O, Matiyash O: Rejuvenating harm reduction projects for injection drug users: Ukraine's nationwide introduction of peer-driven interventions. Int J Drug Policy 2012. 23:141-147

31. WHO, UNODC: Guidance on Testing and Counselling for HIV in Settings Attended by People Who Inject Drugs: Improving Access to Treatment, Care and Prevention. Geneva: WHO; 2009.

32. Broadhead RS, Heckathorn DD, Altice FL, Van Hulst Y, Carbone M, Friedland $\mathrm{GH}$, O'Connor PG, Selwyn PA: Increasing drug users' adherence to HIV treatment: results of a peer-driven intervention feasibility study. Soc Sci Med 2002, 55:235-246.

33. Irwin K, Karchevsky E, Heimer R, Badrieva L: Secondary syringe exchange as a model for HIV prevention programs in the Russian Federation. Subst Use Misuse 2006, 41:979-999.

34. Snead J, Downing M, Lorvick J, Garcia B, Thawley R, Kegeles S, Edlin BR: Secondary syringe exchange among injection drug users. $J$ Urban Health 2003, 80:330-348.

doi:10.1186/1477-7517-10-20

Cite this article as: Ti and Kerr: Task shifting redefined: removing social and structural barriers to improve delivery of HIV services for people who inject drugs. Harm Reduction Journal 2013 10:20.

\section{Submit your next manuscript to BioMed Central and take full advantage of:}

- Convenient online submission

- Thorough peer review

- No space constraints or color figure charges

- Immediate publication on acceptance

- Inclusion in PubMed, CAS, Scopus and Google Scholar

- Research which is freely available for redistribution 